\title{
ANDREI TARKOVSKI: ARTISTA Y HOMBRE ESPIRITUAL
}

\author{
Agustín Garcells
}

Fecha de recepción: abril 2016

Fecha de aceptación: mayo 2016

\begin{abstract}
Resumen:
El presente ensayo constituye un acercamiento al pensamiento del cineasta ruso Andrei Tarkovski. En este sentido, son abordadas en primer lugar, las raíces de este pensamiento dentro de la tradición hesicasta eslava, literaria y filosófico-religiosa. En segundo lugar, se efectúa un análisis de sus concepciones filosófico-religiosas y es téticas, su pensamiento desde el punto de vista teológico, ontológico, antropológico, así como sus definiciones del arte y el cinematógrafo.
\end{abstract}

Palabras claves: Tarkovski, cine, arte, religión, pensamiento

\begin{abstract}
:
This essay constitutes an approach to the thought of the Russian filmmaker Andrei Tarkovski. This analysis focus in the roots of his thoughts within the hesychast Slavic literary and philosophical-religious tradition. Next, an analysis of his philosophical-religious and aesthetic conceptions is performed. This article, as well, studies his thought about the theological, ontological and anthropological point of view and his definitions of art and cinema.
\end{abstract}

Key words: Tarkovsky, film, art, religion, thought

\section{Autor:}

M.Sc. Agustín Garcells Suárez. Cuba, 1979. Licenciado en Historia del Arte por la Universidad de La Habana, Cuba (2003). Licenciado (2011), Máster (M.Sc.) (2012) y Candidato a Doctor en Teología (2012-2018) por la Universidad Aristotélica de Tesalónica, Grecia. Es profesor de Historia del Arte, Teoría del Arte y Estética en la Carrera de Artes Visuales de la Pontificia Universidad Católica del Ecuador en Quito. 


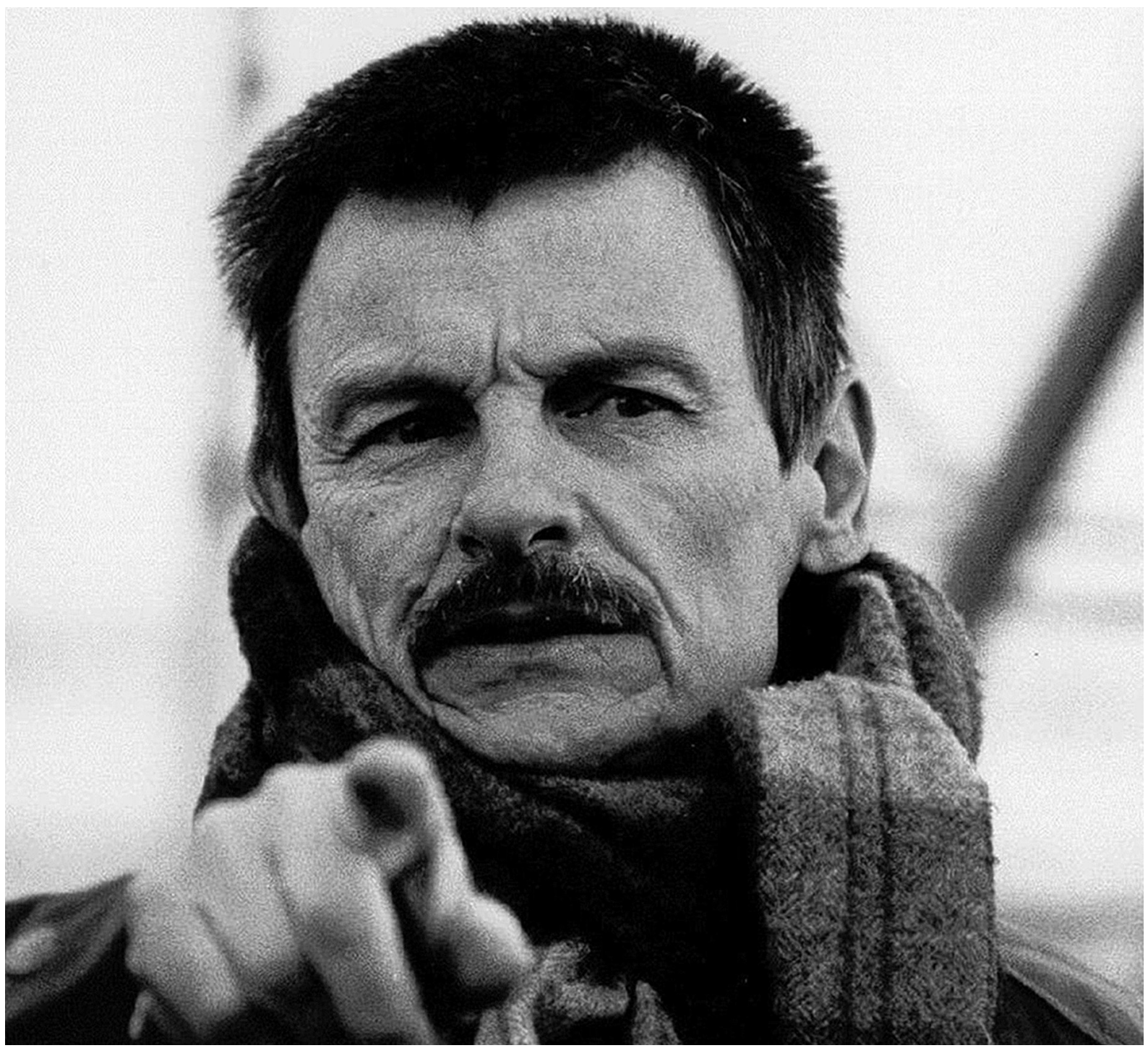

Andrei Tarkovski Festival de Cine Africano de Córdoba

Pero, ¿qué es el arte? ¿Lo bueno o lo malo? ¿Procede de Dios o del diablo? ¿De la fuerza del hombre o de su debilidad? ¿Es quizá una prenda de la comunidad humana y una imagen de armonía social? ¿Es esa su función? (El arte) Es algo así como una declaración de amor. Un reconocimiento de la propia dependencia de otros hombres. Es una confesión. Un acto inconsciente, que refleja el verdadero sentido de la vida: el amor y el sacrificio. (Tarkovski,

2002: 259)

El 29 de diciembre de 1986, desterrado de su patria, Andrei Tarkovski es arrebatado de este mundo. La cámara ha captado por última vez el lugar donde enfrentó la agonía de la enfermedad
(Demant, 1988). Un icono de la Virgen María observa en silencio el lecho de muerte. En la mesa descansan el fonógrafo, los libros, las frutas que no alcanzó a comer. La ventana con vista al jardín permanece abierta. En el saliente yacen amontonadas algunas piedras de río. Parece que esta imagen, miserable y ascética, de algún modo "plenifica" la infinita realidad interior, la libertad del artista inmortalizado.

La literatura y el arte romántico ruso del siglo XIX han dialogado ampliamente con la producción artístico-filosófica del siglo XX. Andrei Tarkovski constituye uno de los más ilustres herederos de esta tradición, que habría 
encontrado en el exilio forzoso una oportunidad de supervivencia y renovación: "Para mí, son extraordinariamente importantes las tradiciones culturales rusas que proceden de Dostoievski... dicha tradición es radicalmente incompatible con el materialismo”. (2002: 218)

En 1901, el pintor realista ruso Ilia Repin (18441930), realiza un retrato del escritor, también ruso, León Tolstoi (1828-1910). En esta obra sobresalen algunos elementos simbólicoalegóricos, a través de los cuales el artista pretendía despertar la conciencia del espectador. En el cuadro aparece representado un anciano pobremente vestido, descalzo, con una larga, canosa y descuidada barba. Desde uno de sus bolsillos asoma tímidamente un ejemplar de las Escrituras. Estos elementos no se encuentran casualmente en la obra, sino con la intención de mostrar la identidad religiosa del escritor. Incluso dialogan de forma más sutil con la "visión de la luz", las "lágrimas del arrepentimiento", la "oración ininterrumpida" y el "enfrentamiento espiritual de la muerte", referentes a los que acude reiteradamente Tolstoi en sus obras. En este sentido, resulta ilustrativo el siguiente pasaje sobre el sufrimiento y la muerte:

Y de pronto se dio cuenta de que lo que lo abandonaba y no acababa de salir, salía repentinamente de todos lados. Sentía lástima por ellos, porque sufrían, y quería hacer algo para que dejaran de sufrir. Para que dejaran de sufrir ellos y él. "¿Qué bueno y sencillo es eso! pensó- ¿Y el dolor? ¿Dónde está el dolor?" Puso atención. "Sí, ahí sigue. No importa. ¿Y la muerte? ¿Dónde está la muerte?" Buscaba la muerte, la buscaba en su anterior miedo, pero este ya no lo sentía, porque la muerte no existía. Había luz en lugar de muerte. — ¡Ahora lo comprendo! — dijo en voz alta—. ¡Qué alegría! Para él sucedió todo en un instante, y la significación de ese instante ya no cambió. Para los presentes su agonía duró dos horas más. En su pecho algo bullía; su pobre cuerpo se estremecía. Después todo fue disminuyendo poco a poco. $-\mathrm{Ha}$ terminado - dijo alguien que estaba cerca de él. El oyó estas palabras y las repitió en su alma: "Ha terminado la muerte. La muerte no existe." Respiró, se detuvo a la mitad, se estiró y murió. (Tolstoi, 2010: 73)

Este pasaje se encuentra impregnado del espíritu de una corriente histórica del cristianismo oriental conocida como "hesicasmo", del griego "hesichia" (silencio). El "hesicasmo" constituye una práctica ascética que tiene como fin, a través del cultivo de la "oración continua del corazón", conquistar la "visión divina”, en griego "theoptía”. El principal representante del "hesicasmo" fue el monje "athonita", posteriormente arzobispo de Tesalónica, Gregorio Palamás (1296-1359). Sin embargo, el ejercicio de la "oración continua" no puede ser fechado con precisión absoluta, aunque está claro que se trata de una práctica muy antigua relacionada con los comienzos del monacato en el desierto. Por lo tanto, el término "hesicasmo" no se limita a la aportación de Palamás y sus contemporáneos del siglo XIV, sino que se extiende a toda la tradición mística de Oriente, sobre todo durante los años del desierto. Es siguiendo esta misma lógica que Nicodemo el Athonita (1748-1809), junto con el obispo Macario de Corinto (1731-1805), publicarían en una imprenta de Venecia en 1782, la famosa antología titulada Filocalia, esto es del griego "amor por el bien o la belleza", donde se reúnen las obras de muchos autores ascetas y Padres de la Iglesia, desde Evagrio Póntico (siglo IV) hasta Gregorio Palamás.

Ya en el siglo XIV, la doctrina de Palamás comienza a impregnar la vida religiosa de Rusia, debido principalmente a la presencia de 
monjes eslavos en el Monte Athos, al contacto con las traducciones eslavas meridionales de la literatura ascética y con el propio monacato meridional. Los estudios contemporáneos han detectado también evidencias del "hesicasmo" ruso ya desde el siglo XI, a pesar que no pueden ser confirmadas debido a la compleja situación política y las devastadoras incursiones de los tártaros.

Dentro de los hesicastas rusos ha pasado a la historia el monje Sergio de Radonezh (13141392), fundador del monasterio de la Santísima Trinidad, también conocido como Zagorsk. En su famosa biblioteca se han encontrado varias traducciones de los discípulos de Gregorio el Sinaíta (1255-1346), máximo exponente e introductor del "hesicasmo" en Bulgaria. En este monasterio se encuentra también la iglesia consagrada a la Santísima Trinidad con los famosos frescos del artista Andrei Rubliev (1360-1430), contemporáneo y discípulo de Radonezh.

El artista y teólogo ruso Leónidas Uspensky (1902-1987), señala que las generaciones de artistas del siglo XIV y XV, eran reconocidas por sus prácticas ascéticas, el ejercicio del ayuno y la oración (1993). Tal es el caso de Andrei Rubliev, pero también de su maestro, Teófanes el Griego (c. 1340 - c. 1410). Según José de Volokolamsk (1439-1515) los pintores rusos de la época "elevaban constantemente el espíritu y el pensamiento a la luz increada y divina" (1993: 306). Acerca de esto Uspensky agrega en su obra exhaustiva sobre el icono: "Un verdadero iconógrafo debe estar en comunicación con el prototipo representado, no solo a través de la participación en el cuerpo de la Iglesia, sino también con su propia experiencia de la santidad”. (319)

Otro personaje decisivo dentro del movimiento hesicasta eslavo, sería el monje ucraniano Paisios Velichkovsky (1722-1794). Este, después de una larga estancia en el Monte Athos (alrededor de dieciocho años), durante la cual aprendería muy bien la lengua griega y copiaría muchos manuscritos de los monasterios griegos y eslavos, terminaría estableciéndose en Neamts de Moldavia, donde fundaría una escuela de lengua griega y una biblioteca. Su destino fue renovar la tradición ascética de los eslavos. En 1793 publica la traducción eslava de la Filocalia, preparada por él mismo en San Petersburgo, con el objetivo de difundir el mensaje hesicasta. Esta versión de la Filocalia incluía, además de la traducción de los contenidos en griego de la primera edición, otros escritos y testimonios de la propia tradición hesicasta eslava. En las bibliotecas de los monasterios de la época, pero también de la aristocracia y la intelectualidad rusas era muy común que se encontraran los ejemplares de esta edición. El teólogo John Meyendorff, haciendo referencia al espíritu hesicasta eslavo, lo ha vinculado directamente con el pasaje de la célebre obra anónima, "Relatos de un Peregrino Ruso", donde puede apreciarse como el personaje, inmerso en su búsqueda espiritual, trata de adquirir una versión de la Filocalia.

Bajo la influencia del referido movimiento hesicasta, aparece también un nuevo centro de peregrinaje espiritual, el monasterio restaurado de Optina, alrededor de 1821. Este era frecuentado desde todos los confines del país por aquellos que necesitaban consejos espirituales. Muchos novicios, pero también laicos aristócratas e intelectuales, se convierten en seguidores de los staretz, que como Serafín de Zarof (17591833), habían calado profundamente el modelo antropológico de la sociedad rusa de la época. Es el caso de los célebres escritores y pensadores, como Nikolái Gógol (1809-1852), Fiódor 
Dostoyevski (1821-1881), Aleksey Khomyakov (1804-1860), Vladimir Solovyov (1853-1900) y León Tolstoi (Meyendorff, 1994: 197), los cuales muestran en su obra todo el imaginario común a la corriente hesicasta. No debe sorprendernos además, que a partir de este momento cierta fisonomía del pensamiento ruso, la más original, se viera en lo que sigue influida a su vez de modo irremediable por este imaginario. Tales son de manera particular el filósofo Nikolái Berdiáyev (1874-1948) y los teólogos Sergei Bulgakov (1871- 1944), Pavel Florensky (1882-1937) y Pavel Evdokimov (1901-1970). La lista se vuelve interminable conforme pasamos por el universo de la literatura -Mijail Bulgakov (1891-1940); el de la música -donde recordamos a Modest Músorgski (1839- 1881), Serguéi Prokófiev (1891-1953), Serguéi Rajmáninov (18731943) - y el del séptimo arte donde se destacan Alexander Sokurov (1951), Pavel Lungin (1949) y en concreto, Andrei Tarkovski, que nació y se formó con la poesía de su padre, el célebre Arseni Tarkovski (1907-1989) y la narrativa de otra leyenda de la literatura universal, León Tolstoi.

Dentro de los límites del presente estudio resulta imposible referirnos a la influencia -intelectual y espiritual- que ejercieron, o pudieron ejercer, la mayoría de estas personalidades en la vida y obra de Andrei Tarkovski. Por esto, hemos decidido referir solo aquellas que se relacionan estrecha y esencialmente con las ideas del realizador ruso y en particular con el profundo contenido de estas ideas.

Tarkovski nació en el año 1932, en Zavrazhie, una aldea ubicada al noreste de Moscú. Sin duda su padre, el poeta Arseni Tarkovski, constituyó la primera influencia artística recibida por el pequeño Andrei. “(... $)^{1}$ y el cielo se abrió ante

1 “(...) voy a comprar una Filocalía y en ella aprenderé la oración interior. Llegué a una ciudad cabeza de partido y me puse a buscar por las tiendas una Filocalía. Encontré nuestros ojos... Mientras seguía nuestra huellas el destino, como el loco, armado de una navaja”. (Arseni Tarkovski, 2011)

Después del divorcio, creció junto a su madre y su hermana menor, leyendo Guerra y Paz, de Tolstoi. Posteriormente estudiaría cine, en la Moscú de 1954, donde tendría su primer contacto con la cultura rusa contemporánea, con su gloria y miseria. En las páginas de su diario puede apreciarse la tragedia que atravesó como ser humano y creador, pero también el regocijo por la presencia de la divinidad: “ $¡$ Siento tu presencia Señor! Siento la palma de tu mano sobre mi cabeza”. (Tarkovski, 2006: 209)

El pensamiento de Tarkovski podría ser clasificado en dos grupos: el filosófico y el estético. No obstante, su "filosofía” y "estética" no pueden entenderse de manera convencional. Estos términos sobrepasan aquí los marcos tradicionales según los cuales suelen encasillarse, esto es, una especie de sincretismo filosófico y eclecticismo estético, que pasaremos a analizar más detenidamente.

Dentro del grupo "filosófico" destaca en primer lugar su concepto de Dios como ente hiperbático, claramente influido tanto por la tradición cristiana, como por la taoísta: "Y todopoderoso, dijo alguna vez Lao Tse es aquello que no percibimos, no escuchamos y no sentimos" (32). Lo cual resulta contradictorio, teniendo en cuenta que esta entidad llega a ser invocada por el propio Tarkovski de manera concreta, mediante la palabra "Señor". Su presencia, como puede verificarse, es incluso experimentada a través de los órganos sensoriales, además de que constituye un lugar común para la práctica

una, pero el librero pedía por ella tres rublos y yo solo tenía dos; en vano intenté convencerle para que me la dejase por dos (...)". (Meyendorff 1994: 181) 
ascética y la agonía espiritual del autor. Así, en el registro de su diario del 7 de abril de 1982, día miércoles (con toda seguridad en la Cuaresma del año), escribe: "Hoy ayuno. No resulta fácil para nada". (345) Del mismo modo, los personajes de sus obras también confrontan su propia "cuaresma”, a través del ejercicio espiritual o la "ascesis", como autoproyección del artista en el caso de sus álter ego más famosos, el pintor Andrei Rubliev y el filósofo Alexander.

En el primer caso, se trata de un monje asceta, discípulo del renombrado hesicasta, Sergio de Radonezh. El presupuesto que consiste en un célebre asceta no puede subestimarse y de hecho, en la cinta, compuesta por una serie de episodios, hay uno en específico titulado "Silencio" donde es posible constatar las prácticas de ayuno y voto de silencio del protagonista.

El otro caso constituye la segunda cinta de corte "político" dentro de su ya connotada "apolíticamente" obra, cuestión que le trajo no pocas disputas con el sistema socialista: "Sacrificio" (1986). En este sentido, podemos recordar también su primer largometraje, La Infancia de Iván (1962) ubicada en el contexto de la Segunda Guerra Mundial. En ambos casos, su primer y último largometraje, entre la Segunda e hipotética Tercera Guerra, es imposible asegurar que la cuestión política resulte esencial, sino que se trata de un pretexto para fundamentar la experiencia del autosacrificio ascético de estos personajes, pero también del estado precario de la humanidad y del peligro que corre la existencia del ser humano:

A mí, como persona con convicciones religiosas, me interesa sobre todo alguien capaz de entregarse en sacrificio, ya sea por un principio espiritual, ya sea para salvarse a sí mismo, o por ambos motivos a la vez. Un paso así presupone apartarse radicalmente de toda intención primaria y egoísta; es decir, esa persona actúa en un estado existencial más allá de la lógica «normal» de los acontecimientos, ha quedado libre del mundo material y de sus leyes. (Tarkovski, 2002: 239)

Por lo demás, el contexto histórico de estas obras sigue pareciendo si no distópico, al menos desprovisto de cualquier referente cronológico decisivo, si se tiene en cuenta que la experiencia "ascética" aquí persigue un fin mayor, cuestión que el autor pretende desvincular de cualquier acontecimiento intrascendente y en virtud de un sentido que pudiéramos caracterizar como escatológico, pero también soteriológico. Al menos, así parece confirmarlo el sacrificio u ofrenda del protagonista de este filme: "Y yo seré mudo, nunca más volveré a hablar con hombre alguno, me separo de todo lo que me une a esta vida. Ayúdame, Señor, y haré todo lo que he prometido hacer". (2002: 248)

Resultan igualmente trascendentales sus nociones acerca de la "verdad". En conexión con su paradójica idea sobre lo divino como "inaprehensible", para Tarkovski la "verdad" también es inaccesible al ser humano. Lo importante es la experiencia que emana de esta búsqueda de la "verdad", a pesar que el artista no llega nunca a establecer una relación concreta entre esta "verdad" y la entidad divina. Esto es, una relación que confirmase el carácter personal de esta "verdad", ya sea como Cristo o cualquier otra entidad, o su carácter filosófico, o tan siquiera de índole abstracta. Como ha podido confirmarse en sus obras, existe un interés muy particular, no solo por la "desmaterialización" de cualquier verdad, sino porque la experiencia de esta verdad resulta relativa, esto es, que la "verdad" constituye, paradójicamente, una búsqueda de la propia "verdad". No obstante, 
esta cuestión parece desarrollarse gradualmente, desde sus primeras películas, donde 1) existe una determinada cuestión teleológica, hasta las últimas, donde 2) no parece existir un objetivo, es decir una finalidad concreta, ya sea en la historia o en la búsqueda existencial de sus personajes.

En lo que respecta al primer caso, el ejemplo paradigmático vendría a ser Andrei Rubliev, una cinta temprana de 1966, donde según el realizador se pone en evidencia su dialéctica entre "verdad histórica" y "falsedad artística" (Tarkovski, 2006, 130). Esto es, que la obra no constituye una biografía en cuanto tal de determinado personaje histórico, sino que en ausencia de biografía alguna, lo que intenta es "re-presentar" a este personaje en un momento específico, sino esencial, de su vida artística. Así, si se tiene en cuenta que constituye un artista, autoproyección del mismo Tarkovski, la cuestión tiene que ver directamente con la creación, en este caso de la obra cumbre del legendario hagiógrafo ruso: La Santísima Trinidad (14221428). Es decir que, lo que pretende el cineasta es que seamos capaces de experimentar cómo el artista consigue interpretar y en qué condiciones se encuentra para interpretar, después de largos años de ejercicio técnico y espiritual, una obra de esa magnitud. El segundo caso es cuando la ausencia de finalidad en la cinta es mayormente evidente, o sea que no demuestra carácter teleológico alguno, como ocurre en el filme de 1979, Stalker. En esta cinta, los protagonistas buscan un lugar, específicamente una habitación, donde sus aspiraciones más profundas se convierten en realidad. Resultando que el misterio de la mencionada habitación nunca se revela, y que la experiencia de la verdad constituye una especie de odisea, con o sin Ítaca incluida, al estilo del poema inmortal de
Constantino Kavafis (1863-1933):

Ítaca te brindó tan hermoso viaje.

Sin ella no habrías emprendido el camino.

Pero no tiene ya nada que darte.

Aunque la halles pobre, Ítaca no te ha engañado.

Así, sabio como te has vuelto, con tanta experiencia,

entenderás ya qué significan las Ítacas. (1982: 61)

No obstante, desconocemos si la poesía de Kavafis formaba parte del acervo literario del cineasta ruso, a pesar de que lo cortés no quita lo valiente, e indudablemente su obra parece estar imbuida del sentido de este poema griego. Una cuestión que a su vez justifica el desarrollo de esta noción por algunos otros realizadores, muchos de ellos seguidores del propio Tarkovski, como el griego Theo Angellopoulos (1935-2012) en La Mirada de Odiseo (1995) y La Eternidad y un Día (1998).

Además, en la conferencia El Nuevo Mensaje del Apocalipsis, el cineasta formula con claridad su "antropología": "El ser humano, como sabemos, fue creado por Dios a imagen y semejanza, es decir que posee libre albedrío y la capacidad de crear" (2003: 74). Este hombre se debate entre la carne y el alma, donde el alma constituye sinónimo de eternidad y el cuerpo de corrupción. Sin embargo, no queda claro aquí a qué se debe esta eternidad del alma, ni siquiera qué constituye exactamente la corrupción del cuerpo, o este dualismo donde el hombre constituye campo de batalla de las fuerzas del bien y del mal. La capacidad de crear constituye también un indicador antropológico relacionado 
con la doctrina cosmológica cristiana: "Fuimos creados a imagen de Dios, y la creatividad es una capacidad que nos instituye como iguales a él" (Cosse, 1986: 69). Para Tarkovski no existe manera de explicar en qué consiste esta capacidad, ni el objetivo concreto que tiene. En todo caso es seguro que no es consecuencia ni de lo que se conoce como virtud o pecado, ni su dialéctica, ni del sentimiento de culpa inherente a esta dialéctica, como usualmente insisten los oscurantistas: la creación es un misterio, o más bien, una especie de milagro. (Konnebäck, 1987)

En lo que respecta a esto último se trata sin dudas de un interesante aporte desde el punto de vista antropológico general y alrededor del cual giran algunas de sus obras. No solo porque ciertos personajes constituyen artistas en efecto, sino porque Tarkovski parece identificarse con esta profesión o vocación, y más específicamente, con estos creadores desde el punto de vista autorreferencial. En este sentido llama la atención esta comprensión del artista como ser humano al cual le resulta imposible la consecución de la felicidad, entendida más bien como un estado pasajero o de entusiasmo en sentido general. Esta cuestión se vuelve cada vez más recurrente entre sus películas, enfocada no solo desde el punto de vista existencial, es decir de aquel artista que busca un sentido a la cuestión creadora, como su Andrei Rubliev, o que ha perdido totalmente la capacidad de producir o la inspiración, como el Pisatel de Stalker; sino a manera de una especie de conciencia autodestructiva. Resulta peculiar que estos personajes o han renunciado a la labor poética, o son incapaces de producir obra alguna, cuestión que se traduce en una especie de hastío, abandono, o también, en peregrinación en busca de la verdad, y que se resuelve maravillosamente con este cine al estilo roadmovies, que tanto parecía resultarle a este realizador ruso.

Sin embargo, la cuestión es que el artista no llega nunca a ser feliz, en tanto se muestra en una actitud ambivalente entre la bondad y la maldad, al estilo más faustiano posible y en este punto tengamos en cuenta específicamente la versión de Thomas Mann. Este artista aparece, ya sea martirizado, coronado de espinas como Pisatel, como Rubliev consumiéndose simbólicamente en una hoguera infernal, o de manera muy particular, en el episodio titulado "Atraco", en la cinta Andrei Rubliev. Aquí, el hagiógrafo ruso, después de cometer un homicidio, aparece representado en una escena exquisitamente sincrética, aparentemente ocupando el lado oscuro del yin y el yang oriental. Elemento que se vería complementado en el último episodio, "La Campana", específicamente en la última escena, donde Rubliev interpreta una especie de papel maternal y redentor, una recomposición de "La Piedad" de Miguel Ángel, que viene a confirmar definitivamente, la existencia de una dialéctica entre el bien y el mal en la obra fílmica de Andrei Tarkovski.

Incomparablemente conmovedoras resultan también sus nociones sobre la "inmortalidad". La muerte constituye una noción dinámica, esto es, nada en sí misma, sino en virtud del dolor, la enfermedad y la sensación de abismo: "Sin embargo, ¿qué sabemos sobre la muerte? Aquí no sabemos nada sobre la vida... Y cuando averiguamos algo, intentamos olvidarlo" (Tarkovski, 2006: 223). Igualmente, en este caso resulta perceptible la influencia, en primer lugar del autor de La Muerte de Iván Ilich y luego de su padre, el poeta Arseni Tarkovski:

No creo en los augurios, ni temo a las señales. No temo ni a la superstición, ni huyo del veneno. La muerte no existe. Todos son inmortales, todo es inmortal. No debes temer a la muerte 
ni a los diecisiete, ni a los setenta. No existe la muerte, ni la oscuridad. Existe solo la luz y la realidad. Estamos todos en la orilla opuesta del mar y yo soy uno de aquellos que arroja sus redes, al tiempo que la inmortalidad desfila ante mí como un rebaño. (Arseni Tarkovski, 2012)

No obstante, este tema de la inmortalidad no parece ocupar directamente a Tarkovski en sus obras, con la excepción de su diario y algunas conferencias o entrevistas, anteriormente referidas. Pero hay que señalar que la muerte sí constituye un evento peculiar y que ha merecido un tratamiento muy cuidadoso por parte de este realizador. El tema en cuestión emana como una especie de aprehensión, no solo porque el temprano y trágico deceso de Tarkovski circunda misteriosamente su obra, sino porque en sentido general, la muerte aquí constituye una experiencia catártica efectiva. En este sentido, es posible constatar una serie de recursos simbólico-alegóricos que son utilizados para detonar períodos específicos de angustia en el espectador.

En primer lugar, habría que mencionar su ópera prima, La Infancia de Iván, no solo porque se trata en efecto de la muerte de un niño, una verdadera tragedia, sino porque la cuestión viene anticipándose sutilmente durante toda la cinta. Pero lo mejor de todo es que Tarkovski no necesita que el espectador constate directamente ninguna muerte, sino que a través de una serie de indicios y un catalizador visual, una fotografía del niño, es posible experimentar este acontecimiento con toda su magnitud. En segundo lugar está esa especie de espíritu profético, trágico también, que circunda su obra, sobre todo desde "Nostalgia" en 1983, una cinta que medita profundamente acerca de la nostalgia por la patria, de cómo esta experiencia afecta al protagonista ruso y por extensión, al propio Tarkovski:

¿Cómo iba a imaginar durante el rodaje de "Nostalghia" que aquel estado de tristeza aplastante y sin salida, que marca toda la película, podría alguna vez ser el destino de mi propia vida? ¿Cómo iba a imaginar que yo mismo, hasta el final de mis días, tendría que sufrir esa misma grave enfermedad? (Tarkovski, 2002: 226)

La profecía aquí va más allá del autoexilio, de la condición de emigrante que tendría que asumir el propio Tarkovski y se extiende a la posibilidad más peculiar: la muerte. Así lo testifica y profetiza la cinta, a través de la lectura de una epístola a un amigo, del músico Pavel Sosnovski:

Tenía miedo porque sabía que no
había sido un sueño, sino mi realidad,
y que moriría si nunca pudiese volver a
Rusia. Si nunca volviese a ver mi país
natal, los abedules, el aire de mi niñez.
(Tarkovski, 1983)

De la misma manera ocurre con su última película, "Sacrificio" de 1986, donde también existe esa atmósfera que anticipa todo tipo de desenlace trágico. Una mención especial merece sin embargo, la cuestión que tal y como había concebido originalmente la cinta el propio Tarkovski, el protagonista Alexander padecía de cáncer en estado terminal. Ha venido a resultar curioso que el actor preferido del realizador ruso, Anatoliy Solonitsyn (1934-1982), y que supuestamente debía interpretar este papel algún día, fallecería también de cáncer:

Anatoli Solonitsin murió de la misma enfermedad que cambia la vida de 
Alexander, la misma que hoy, años después, me afecta también a mí. ¿Qué significa todo esto? No lo sé. Solo puedo darme cuenta de lo siguiente: una imagen poética, que he creado en algún momento, se convierte en realidad concreta, palpable, se materializa y - lo quiera o no- empieza a ejercer influencia en mi vida. (2002: 287)

En lo que respecta a la cuestión de la inmortalidad, habíamos dicho que no aparece representada directamente, pero sí de manera implícita, emparejada con una serie de conceptos metafísicos ya tradicionales dentro de la cultura occidental. En este sentido podemos identificar claramente tres tipos de "inmortalidad", si es que puede llamarse de esta manera, en la medida que se pueden entender incluso, como variantes específicas de la cuestión de la "resurrección" o la "trascendencia", que como hemos referido resulta una temática con recurrencia particular en nuestra cultura.

En primer lugar, encontramos una forma de trascendencia que vamos a denominar "estética", y que aparece representada de manera bastante elocuente en la cinta Andrei Rubliev, específicamente en el epílogo, donde es posible apreciar una especie de secuencia de imágenes presentada a todo color. Esta consiste en una parte selecta de la obra del hagiógrafo ruso, en contraste con la película filmada completamente en blanco y negro. Aquí la obra del hagiógrafo viene a ser una forma específica de trascendencia, y se representa a color en la medida que constituye una "restauración" o "recapitulación" de la propia vida de Rubliev, en contraposición a la aparente falta de equilibrio o perfección del pasado, cuestión que sugiere la imagen en blanco y negro.
Otro género de inmortalidad o trascendencia, es el que denominaremos "filosófico", no exento de cierto sentido místico, y que puede constatarse en su último filme, "Sacrificio". En esta historia, el personaje ofrenda, se desprende, de todo aquello que lo constituye principalmente como humano, desde el habla y sus pertenencias, hasta toda lógica, con un fin soteriológico. No obstante, el hecho que, demente y desalmado, termine conducido hacia un hospital psiquiátrico, no constituye todavía la imagen restaurada o inmortalizada de este ser humano, sino de la renuncia o ascesis en virtud del mencionado sentido soteriológico, cuestión que aparece representada un poco más tarde, en la figura de su hijo que cierra la película con una frase: "En el principio estaba la Palabra. ¿Por qué es eso, papá?”. Una frase que viene a complementar la inquisición anterior de su padre, al principio del filme, en un momento que su hijo no podría responderle porque se encontraba literalmente mudo: "En el principio estaba la Palabra. Pero estás mudo, mudo como un pez". (Tarkovski, 1986)

Por último, está la inmortalidad propiamente dicha, y que en consecuencia debemos nombrar como "religiosa", porque remite directamente a la cuestión del cristianismo, en específico a lo que se entiende aquí como "trascendencia": la Resurrección. El tema aparece representado también, en la cinta Andrei Rubliev, en el mismo episodio titulado "Atraco" donde Rubliev acaba de perpetrar un homicidio. Aquí se efectúa un diálogo entre el hagiógrafo ruso y su maestro, Teófanes el Griego, que habría muerto en algún momento anterior del filme. La escena en particular, muestra determinada sensibilidad desde el punto de vista hagiológico, y que se resuelve reservando para el "finado" los valores más claros de la composición, mientras que para 
el homicida, la oscuridad. De más esta decir, que este "finado" no es tal en el sentido estricto de la palabra, sino una especie de imagen gloriosa de Teófanes inmortalizado, una prefiguración de la "Anástasis" cristiana.

Asimismo, entre sus concepciones estéticas destaca su definición de la obra de arte como plegaria (De Baecque, 1991: 153). Esto es, que un filme se encuentra elaborado de facto, como una especie de plegaria, y que esta consiste en una manera de retroalimentación entre el ser humano y la entidad sobrenatural, como ocurre de hecho en "Sacrificio", donde existe demanda (la salvación), pero también una determinada oferta (la privación o ascesis). Según Tarkovski, al arte como plegaria y modo peculiar de conocimiento de la "verdad" se opone la "ciencia", en este caso como percepción objetiva de la realidad. Mientras la ciencia se caracteriza por la producción de objetos, ideas o conceptos, el arte se encarga de plasmar lo "impracticable" e "incognoscible", es decir, la "verdad" misma: "El poder del arte es el propio arte, la expresión de un fenómeno inexplicable que no puede subordinarse a la voluntad de los hombres, ni de los sistemas" (Basileiadis, 2003: 117). Lo cual no significa que el arte verdadero se encuentre alienado de la realidad, ni tampoco que siempre deba expresarla de manera literal, sino que esta realidad, es decir el entorno social y étnico también, del artista, constituye el único medio disponible a fin de realizar la función suprema del arte: la manifestación de la "verdad".

Una cuestión que presupone, en parte, que las realizaciones de Tarkovski siempre ponen una distancia entre estas y la realidad, que se fundamentan en una especie de poética o estética "antimimética", considerando que la esencia del arte es ante todo, expresión o reproducción de la "verdad", en contraste con la esencia de la técnica, que consiste en sustitución de la "verdad" o la "realidad". Sin embargo, es imposible además la "desparticularización" del arte desde el punto de vista "etnocéntrico", tomando en cuenta que el artista no sería capaz de realizar semejante tipo de alienación. Un ejemplo de esto vendría a ser en Andrei Rubliev, la representación de la Crucifixión en el episodio titulado "La Pasión de Andrei Rubliev". En esta escena el drama del Gólgota ha sido representado en el contexto ruso $y$, específicamente entre las nieves, una especie de recreación de Dios a imagen y semejanza del propio Tarkovski.

A todo lo anterior, habría que sumar también, en sintonía con la noción de Dostoievski, "la belleza salvará al mundo", que Tarkovski considera que la belleza propicia la instauración auténtica de la verdad: "Lo bello queda oculto a los ojos de aquellos que no buscan la verdad" (2002: 65). Y como el arte constituye una manera de apresar lo invisible, lo impracticable, es precisamente por esto que deviene también en un símbolo, entendido como "jeroglífico" de la "verdad" (61), como "sustituto" , o más bien, expresión material y ascética, de lo inaprehensible. Ascética porque lo simbólico se caracteriza por una especie de simplicidad, privación, en comparación con el referente de todo arte, incomparable, incognoscible e irrepresentable. En resumen, que la obra de arte no pretende ni transmitir ideas, ni enseñar algo en específico más allá de aquello que encontramos en concordancia con su objetivo supremo, es decir el "conocimiento" o experiencia de la propia "verdad".

Aquello que, sin embargo, constituye imprescindible dentro del proceso artístico es el nivel espiritual del espectador: "El arte surge y se desarrolla allí donde hay ese ansia eterna, incansable, de lo espiritual, de un ideal que hace que las personas se congreguen en torno al arte" 
(61). La palabra "ansia" aquí no hace referencia a la búsqueda de determinado conocimiento en el sentido positivo del término, sino a la creencia, la fe de que existe "verdad". Porque el objetivo final resulta la recapitulación, restauración, catarsis o purgación del hombre, a pesar que el término "purgatorio" para Tarkovski, no posee el significado eclesiástico tradicional. En este sentido, resulta significativo cómo otorgaba particular atención a las cartas que recibía de sus admiradores y detractores, y en específico aquellas que provenían del público más sencillo, pero más espiritual:

¿De qué trata esta película (El Espejo)? Del hombre. Por supuesto que no de aquel hombre concreto (...) No. Es más bien una película sobre ti mismo, sobre tu padre y tu abuelo. Una película sobre el hombre, que vivirá cuando tú hayas muerto, pero que será un “Tú”. Es una película sobre el hombre que vive sobre la tierra $\mathrm{y}$ es parte de la tierra, que a su vez es parte de ese hombre. Una película sobre el hecho que el hombre ha de responder con su vida ante el pasado y ante el futuro. Esta película hay que verla, eso es todo, escuchando devotamente la música de Bach y las poesías de Arseni Tarkovski. Y hay que verla como se contemplan las estrellas, el mar o un paisaje bello. Se echará de menos la lógica matemática. Pero esta, en el fondo, no explica qué es el hombre y en qué consiste el sentido de su vida. (Carta de un admirador, en Tarkovski, 2002: 26)

En lo que a esto respecta, es importante subrayar también, que Tarkovski confiere al hecho artístico un significado ético medular dentro de la sociedad, el cual estriba en la capacidad del arte de producir "cultura". Pero, la actitud de esta "cultura", de esta "sociedad", debe constituir la más peculiar, la más esencial, en este caso la preparación del ser humano para el acontecimiento más singular de su existencia: la muerte.

En lo referente al sujeto creador, es decir al artista, sobresale su paradójico rol: "Talento significa desgracia, porque en primer término no puedes pedir que te respeten o te admiren por tenerlo, luego te crea descomunales obligaciones" (2006: 71). El artista parece confirmar la tragedia de la vida humana, quizás en su forma más extrema porque posee autoconocimiento de la paradoja de su existencia y sacrificio inevitable, algo que le viene como una especie de destinación, en última instancia.

Por último, resulta ineludible hacer referencia a su original reflexión acerca del cinematógrafo. Para Tarkovski, el cinematógrafo constituye una manifestación legítima y singular dentro del universo artístico, es decir que no consiste en una amalgama o síntesis de todas las artes tradicionales, sino que posee su propia naturaleza. Esta es una de las razones por las que sus películas que resultan adaptaciones de títulos literarios, terminen como versiones libres de estos textos. No obstante, la definición de cinematógrafo aquí, presupone primero el concepto de arte ya mencionado, esto es como medio de "conocimiento" y "experimentación" de la verdad. Sin embargo, desde el punto de vista "hipostático" presenta una "sustancia" distinta, absolutamente singular, la cual es intervenida por el artífice o realizador, de manera incomparablemente efectiva: el tiempo.

Este "tiempo" deja de ser una dimensión abstracta, por el simple hecho que en el cine se presenta en forma de acontecimientos. 
Resulta una forma sui generis de la memoria, un artificio que para Tarkovski constituye en sí mismo la manera más compleja de almacenar acontecimientos, aunque lo importante es que no se almacena nunca cualquier acontecimiento, sino aquel que resulta esencial. Este consiste también en una peculiar concepción de la "memoria", donde se presupone también que la forma ideal del tiempo es el pretérito. Ni el presente, ni el futuro es posible experimentarlos de forma medular.

Por su parte, la memoria biológica resulta imposible de objetivar completamente, del mismo modo que las ciencias históricas y las artes tradicionales, por el carácter subjetivo implícito en su naturaleza. La cuestión, según Tarkovski y desde una perspectiva histórica, siempre pareció residir en la posibilidad de almacenar el tiempo como acontecimiento. Además, habría que preguntarse a estas alturas en qué consiste un acontecimiento y cuáles de sus particularidades permanecen intactas desde el punto de vista histórico, cuestión que resulta imposible de resolver en estas líneas.

Para Tarkovski, esta necesidad de objetivación del tiempo se vería resuelta en 1895 con el nacimiento del cine. Dice:

\section{(...) el hombre, por primera vez en la} historia del arte y de la cultura, había encontrado la posibilidad de fijar de modo inmediato el tiempo, pudiendo reproducirlo todas las veces que quisiera. Con ello el hombre consiguió una matriz del tiempo real (2002: 83).

En este sentido, el carácter tecnocrático implícito a esta manifestación del arte, constituye un sacrificio desde el punto de vista artístico, en virtud del fin, que consiste en la posibilidad de plasmar el tiempo e intervenir de la manera más objetiva posible sobre él, incluso perfeccionándolo. Es en este punto donde concibe su profundo concepto del arte fílmico como "esculpir en el tiempo", noción que estuvo poniendo en práctica durante toda su obra:

Del mismo modo que un escultor adivina en su interior los contornos de su futura escultura sacando más tarde todo el bloque de mármol, de acuerdo con ese modelo, también el artista cinematográfico aparta del enorme e informe complejo de los hechos vitales todo lo innecesario, conservando solo lo que será un elemento de su futura película, un momento imprescindible de la imagen artística, la imagen total (2002: 84).

Para finalizar, hay que añadir que esta definición del cinematógrafo no cambia de ninguna manera el ya referido concepto de arte, sino que lo enriquece a partir del descubrimiento de una nueva manera de conocimiento de la realidad, que presupone también la conformación de una nueva versión de la subjetividad. Aunque lo más importante es, a fin de cuentas, que la "verdad" haya encontrado una forma nueva y universal de manifestarse, de tal manera que la obra de arte, esa "plegaria" singular según Andrei Tarkovski, a partir de la "objetivación" del tiempo, funge como medio de "comunicación" entre los seres humanos. 


\section{Bibliografía}

Basileiadis, G. (2003). Andrei Tarkovski, Thessaloniki: Aigokeros.

Cosse, L. (1986). Andrei Tarkovski: O ouranos den einai adeios. Synaxi, Volumen 19, p. 69.

De Baecque, A. (1991). Andrei Tarkovski. Mia xenagisi sto ergo tou. Trikala: Gobostis.

Demant, E. (1988). Auf der Suche nach der verlorenen Zeit. Andrej Tarkowskijs Exil und Tod. [Documental]. Alemania.

Kavafis, K. (1982). Poesía Completa. Titivillus.

Konnebäck, L. (1987). Enterview with Andrei Tarkovsky. Third Way, Volumen 10 no.1. p. 20.

Meyendorff, J. (1989) O agios Gregorios o Palamas kai h orthodoxi mistiki paradosi. Athena: Akritas.

Tarkovski, A. (2006). Martyrologio, Athena: INDIKTOS.

Tarkovski, A. (2003). To neo minima tis Apokalipsis en 4x5. Einstein, Tagore, Grotovski, Krishnamurti, Tarkovski. Thessaloniki; Archetypo, 2003, pp. 71-90.

Tarkovski, A. (2002). Esculpir en el Tiempo. Madrid: RIALP.

Tarkovski, A. (1962). La Infancia de Iván [cinta cinematográfica]. Unión Soviética: Mosfilm.

Tarkovski, A. (1966). Andrei Rubliev [cinta cinematográfica]. Unión Soviética: Mosfilm.

Tarkovski, A. (1972). Solaris [cinta cinematográfica]. Unión Soviética: Mosfilm.

Tarkovski, A. (1975). El Espejo [cinta cinematográfica]. Unión Soviética: Mosfilm.
Tarkovski, A. (1979). Stalker [cinta cinematográfica]. Unión Soviética: Mosfilm.

Tarkovski, A. (1983). Nostalgia [cinta cinematográfica]. Italia, Unión Soviética: Opera Film Produzione, Rai 2, Sovinfilm.

Tarkovski, A. (1986). Sacrificio [cinta cinematográfica]. Suecia, Reino Unido, Francia: Svenska Filminstitutet (SFI), Argos Films, Film Four International.

Tarkovski, Arseni (2011, diciembre, 10). Los primeros encuentros. El Placard. Recuperado de http://el-placard.blogspot.com/2011/12/ poemas-de-el-espejo-arseny-tarkovsky.html

Tarkovski, Arseni (2012, diciembre, 11). Zoi, Zoi. Ithaque.gr. Recuperado de http://ithaque. gr/zoi-zoi/

Tolstoi, L. (2010). La Muerte de Ivan Ilich. Buenos Aires: Lectorum, S. A.

Uspenski, L. (1993). H Theologia tis Eikonas stin Orthodoxi Ekklisia. Athena: Armos. 